\title{
Places and Preferences: A Longitudinal Analysis of Self-Selection and Contextual Effects
}

\author{
AINA GALLEGO, FRANZ BUSCHA, PATRICK STURGIS AND DANIEL OBERSKI*
}

Contextual theories of political behaviour assert that the contexts in which people live influence their political beliefs and vote choices. Most studies, however, fail to distinguish contextual influence from self-selection of individuals into areas. This article advances understanding of this controversy by tracking the left-right position and party identification of thousands of individuals over an eighteen-year period in England before and after residential moves across areas with different political orientations. There is evidence of both non-random selection into areas and assimilation of new entrants to the majority political orientation. These effects are contingent on the type of area an individual moves into and contextual effects are weak and dominated by the larger effect of self-selection into areas.

It is unexceptional to remark that the political preferences of a national population are not randomly distributed across geographical areas. We know considerably less, however, about how this spatial clustering comes about. Contextual theories of political behaviour assert that elements of the environment in which individuals are situated exert a causal influence on the political parties and policies they prefer. ${ }^{1}$ People, the argument goes, progressively assimilate through a variety of social-psychological mechanisms to the dominant political orientation of the environments in which they live. Consistent with these theories, a long tradition of research in electoral geography has examined the cross-sectional correlation between individual political preferences and social and political characteristics of local contexts. ${ }^{2}$

Despite the large body of existing research in this area, however, the question of whether local contexts actually cause political preferences to change remains contested. Scholars have long argued that the correlation between individual political preferences and contextual characteristics is driven, in whole or in part, by self-selection of people into areas with

* Gallego: Institut de Barcelona d'Estudis Internacionals (email: agallego@ibei.org); Buscha: Department of Economics and Quantitative Methods, University of Westminster (email: buscha@westminster.ac.uk); Sturgis: Department of Social Statistics and Demography, University of Southampton (email: p.sturgis@ soton.ac.uk); Oberski: Methodology Department, Tilburg University (email: d.1.oberski@tilburguniversity. edu). The authors gratefully acknowledge the support of the Economic and Social Research Council through the grant for the National Centre for Research Methods (NCRM; grant reference: RES-576-47-5001-01) and from the Marie Curie Actions of the European Union's Seventh Framework Programme under REA grant agreement no. 334054 (PCIG12-GA-2012-334054). The code utilized to produce the results is posted in the BJPS repository. Data replication sets and online appendices are available at http://dx.doi.org/doi: $10.1017 /$ S0007123414000337.

The British Household Panel Study, however, does not allow dissemination of the micro-data.

1 Agnew 1987; Books and Prysby 1988; Burbank 1997; Cox 1969; Ethington and McDaniel 2007; Huckfeldt and Sprague 1995; Johnston and Pattie 2006.

2 Andersen and Heath 2002; Butler and Stokes 1974; Crewe and Payne 1976; Johnston et al. 2004; Johnston, Pattie and Allsopp 1988; McAllister et al. 2001; Miller 1978. 
congruent political beliefs. ${ }^{3}$ It is our contention in this article that this longstanding debate remains unresolved because previous studies based on cross-sectional data have not been able to separate self-selection and contextual effects from one another convincingly. Although falling some way short of the gold standard of random assignment of individuals to areas, a longitudinal research design provides a considerably more satisfactory means of identifying the independent effects of assimilation and self-selection. This is because panel data enable the tracking of changes in political preferences before and after individuals move to contexts with different political majorities. Yet, because of the strong data requirements that longitudinal approaches impose, few examples of this type of strategy can be found in the existing literature.

This article advances understanding in this area by assessing the causal effect of contexts on individual political orientations by tracking the preferences of individuals before and after residential moves, over an eighteen-year period. We do not seek to address the full range of causes and political consequences of internal migration, but focus our attention on two narrow yet fundamental research questions: Do people select into areas that exhibit majority political beliefs congruent with their own? And are individual political preferences influenced by the political orientation of the area into which an individual moves? To foreshadow our later results, our findings show that people are more likely to choose areas in which to live that are congruent with their pre-existing political preferences. Yet political orientation plays only a very limited, if any, role in location choice. Rather it is the socio-economic characteristics of individuals that are correlated with political preference, such as work and parental status, which are consequential in this regard. Self-selection into areas occurs, in short, for non-political reasons. We also find that in the years following a residential move, an individual's political preferences become more aligned with the majority political orientation of the area into which they moved. However, this process of assimilation is both weak and contingent upon area type; in England only those moving into strongly Conservative areas from other types of area exhibit evidence of contextual effects.

Establishing that both self-selection and, albeit limited, contextual effects exist is important for several reasons. In a fundamental sense, it provides political scientists with a better understanding of the origins of political preferences. From a more practical perspective, both processes are likely to have important political consequences because they produce, over time, more spatially polarized political preferences. In politically homogeneous communities, residents are less likely to be exposed to diverse opinions, with negative implications for social and political tolerance, and the majority party will have larger margins of victory, resulting in less competitive elections. Geographical polarization of political preferences has also been shown to generate electoral biases in the translation from votes to seats in majoritarian systems and affects the incentives of parties to modify their policy platforms. ${ }^{4}$

The remainder of this article is structured as follows. First, we review the existing literature on the geographical clustering of political preferences. A discussion of the limitations of existing methodological approaches to untangling contextual effects and selection mechanisms leads us to conclude that a longitudinal research strategy is required. We then describe the dataset and key measures to be used in our analysis and detail our model-fitting strategy, before presenting our empirical results. We conclude with a discussion of the limitations of our own approach and a consideration of the substantive implications of our findings.

3 Dunleavy 1979; Kelley and McAllister 1985; King 1996; McAllister and Studlar 1992.

${ }^{4}$ Chen and Rodden 2009; Rodden 2010; Rodden 2012. 
THE SOURCE OF THE SPATIAL CLUSTERING OF POLITICAL PREFERENCES: CONTEXTUAL EFFECTS OR SELECTION?

Scholars have argued that contextual influence occurs through a variety of social-psychological mechanisms, ${ }^{5}$ including interpersonal contact and persuasion, ${ }^{6}$ party mobilization, ${ }^{7}$ exposure to shared local socio-economic conditions, ${ }^{8}$ common local interests, ${ }^{9}$ and exposure to lowintensity information cues. ${ }^{10}$ For instance, theories of interpersonal contact argue that members of the political majority will tend to have their views reinforced, whereas those in the minority will change their views through processes of persuasion and conformity, generating a more homogeneous community outlook over time. Strong local party branches can also persuade local residents to change their political views through outreach activities.

A large body of empirical evidence supports the main prediction of contextual theories in showing that there is a robust correlation between individual political preferences and area-level characteristics. For instance, Butler and Stokes showed that residents of British parliamentary constituencies vote for the local majority more frequently than would be expected for the population as a whole. ${ }^{11}$ Similar correlations between measures of aggregate political orientations and individual political preferences have been replicated many times since. ${ }^{12}$ Other studies have shown that socio-economic characteristics of neighbourhoods, variously defined and measured, predict vote choice above and beyond individual level characteristics. ${ }^{13}$ Many studies have also found evidence consistent with the mechanisms hypothesized to underpin assimilation effects, such as interpersonal discussion or political mobilization. ${ }^{14}$

While the large majority of existing studies rely on cross-sectional evidence, some have used short-run panels. Pattie and Johnston examined the characteristics of individuals who switched parties between the 1987 and 1992 general elections in Britain and found that people reporting discussion partners who supported a different party were more likely to have changed allegiance. ${ }^{15}$ Johnston et al. showed with data from the British Household Panel Survey (BHPS) that people in the same constituency had changed their votes in similar directions across elections in 1992 and 1997, leading them to conclude that 'place matters'. ${ }^{16}$ However, these two-wave studies remain somewhat inconclusive about causal order. That is to say, it may be the case that individuals who do not identify strongly with a party are both more likely to select discussion partners with different opinions and to switch parties. Hence, with only a few exceptions, it is still true that 'the standard approach in studies of context is to examine the effect that an aggregate-level compositional measure has on an individual behavior or attitude ... covariation between the individual variable and aggregate variable is taken as evidence of a contextual effect'. ${ }^{17}$

\footnotetext{
5 While existing work focuses mostly on social mechanisms, other contextual characteristics such as climate or geographic features can also conceivably affect political behaviour.

6 Butler and Stokes 1974; Huckfeldt, Ikeda and Pappi 2005; Huckfeldt and Sprague 1995.

7 Denver and Hands 1997; Pattie, Johnston and Fieldhouse 1995.

8 Books and Prysby 1988.

9 Cutler 2007.

10 Cho and Rudolph 2008; Huckfeldt and Sprague 1992.

11 Butler and Stokes 1974.

12 E.g. Cox 1969; Crewe and Payne 1976; Taylor and Johnston 1979.

13 E.g. Andersen and Heath 2002; Johnston, Pattie and Allsopp 1988; Johnston et al. 2005; McAllister et al. 2001; Miller 1978.

14 For a review, see Johnston and Pattie 2006.

15 Pattie and Johnston 2000.

16 Johnston et al. (2001), p. 107.

17 Baybeck and McClurg (2005), p. 494.
} 
There are good reasons to assume that an individual's choice of a residential location will be correlated with prior political preferences. While it is unlikely that political preferences have a strong direct causal effect on residential choices, an indirect influence seems more plausible. This is because, when deciding where to relocate, movers must balance a broad range of preferences and constraints, including local housing prices, distance to work, quality of services, and tastes over the type of neighbourhood and the features of the house. ${ }^{18}$ Political preferences are correlated with the socio-economic characteristics that constrain the choice of destination, such as income and family situation. Preferences are also correlated with tastes for many types of public goods (safety, scenic landscapes, cultural events, nightlife) which different localities provide. ${ }^{19}$ Because of differences in both socio-economic constraints and location preferences we expect that those on the left and on the right will exhibit different location choices when they move and, specifically, that they will be more likely to move to politically like-minded communities.

Recent research on the dynamics of partisan support have shown that, in the United States at least, movers tend to select areas that have majority political preferences more similar to their own than their original location. ${ }^{20}$ While these studies provide evidence of non-random selection into areas, they tell us nothing about contextual effects and do not examine whether self-selection is political in nature. Consistent with the view that self-selection trumps contextual effects, critics of contextual effect theories have pointed out that the correlation between contextual characteristics and individual preferences generally becomes negligible, or zero, when controlling for individual level characteristics. ${ }^{21}$ Hence, summarizing the critics' position in the debate, King concludes: 'The geographical variation is usually quite large to begin with, but after we control for what we have learned about voters, there isn't much left for contextual effects'.22

Concerns about selection bias can, of course, be mitigated by controlling for socio-economic characteristics, which influence both the propensity to move and political preferences. A conditioning strategy, though, requires that all the requisite control variables are known and measurable, which seems unrealistic given that many of the candidate variables are notoriously difficult to measure in surveys (for example, housing tastes, early socialization experiences, personality). Thus, statistical control using cross-sectional data is unlikely to be a wholly effective strategy for dealing with selection bias. In summary, despite advances in both data and method, doubts remain over the core claim of theories of contextual effects: that contexts cause changes in political attitudes and behaviour.

A more robust strategy for estimating the effects of contexts on political preferences is to make use of data containing longitudinal information about the same individuals over time. The primary advantage of repeated measurements or panel data is that, under certain model specifications, it is possible to partial out all observed and unobserved time-invariant characteristics of individual units. ${ }^{23}$ As Halaby puts it, "the problem of causal inference is fundamentally one of unobservables, and unobservables are at the heart of the contribution of panel data to solving problems of causal inference'. ${ }^{24}$ The incorporation of a longitudinal

18 Rabe and Taylor 2010.

19 E.g., see Florida (2003) on cities of the creative class; and Tiebout (1956) on political orientation and preferred bundles of taxes and services.

${ }^{20}$ Cho, Gimpel and Hui 2012; McDonald 2011.

21 Kelley and McAllister 1985; McAllister and Studlar 1992.

22 King (1996), p. 160.

23 Halaby 2003; Halaby 2004; Wooldridge 2002.

24 Halaby (2003), p. 2. 
dimension yields crucial additional leverage on questions of causal order, making it possible to model within-individual change as a function of preceding events. ${ }^{25}$ Because this approach is based on the analysis of change in both dependent and independent variables within individuals over time, the estimated model coefficients are purged of the effects of all fixed (or 'timeinvariant') respondent characteristics. Such fixed characteristics comprise both the 'usual suspects' such as gender, age cohort, and ethnicity, as well as less easily measurable variables such as personality traits and pre-adult socialization experiences. We are unaware of any existing study which has used this type of design to evaluate the extent and magnitude of selfselection and political assimilation to areas. This article has been motivated by the need to address this longstanding lacuna.

\section{DATA AND METHODOLOGY}

To estimate the effect of area-level political orientation on individual political preferences, we have used the BHPS. We tracked individuals who moved across electoral constituencies over an eighteen-year period and observed whether movers were more likely to choose constituencies where their pre-existing views were closer to the views of existing residents than other potential choices of location (self-selection). Additionally, we evaluated whether the self-selection effects observed were political in nature, which is to say that individuals chose 'like-minded' areas because of their political orientation. We also assessed whether individuals adopted the political preferences prevalent in their new contexts over time.

\section{Sample}

The BHPS is a large, high-quality repeated measures survey in which a stratified, multi-stage, random sample of British households had been interviewed annually since 1991. Computerassisted face-to-face interviews were attempted with all household members aged 16 years or older. The initial Wave 1 household response rate was 74 per cent. Extensive efforts were made to track responding individuals across waves when a household had moved address, or when an individual moved from an existing household to a new one, such as when adult children had left home, or when a cohabiting couple separated. The study achieved a tracking rate averaging 95 per cent across all waves. The BHPS was thus ideally suited to our objectives because it contains a large number of residentially mobile individuals for whom self-reports of political preferences are observed before and after a move.

Our analysis uses eighteen waves of data from 1991 to 2008 inclusive, with almost 10,000 individuals clustered within over 5,000 households in the first wave (1991). We restrict our focus to England only, excluding households in Wales, Scotland and Northern Ireland because the party systems in these countries are sufficiently different from England to make combined analyses difficult to interpret. We also exclude observations of those aged under 18 in order to match our analysis sample with the voting age population in England. We include "new sample members' who join the BHPS through the formation of new households with 'original sample members' as well as 're-entrants' (i.e. those who had been non-respondents in the previous wave). These inclusion criteria yield an analysis sample of 17,373 individuals, who provide a combined total of 158,000 unique observations over the eighteen waves. The average number of waves completed by individuals is 9.14 and 4,100 individuals responded in all eighteen waves. To deal with the issue of non-random attrition, we include a range of control variables that predict drop-out from the study. Our estimates are, therefore, unbiased

${ }^{25}$ Allison 1994. 
under the 'missing at random (MAR)' assumption, which we consider to be plausible in the current context. ${ }^{26}$

\section{Individual Political Preferences}

The BHPS offers two options for specifying individual political preferences. The first is a standard measure of party identification, which was administered in all eighteen waves; the second is a multi-item scale designed to measure people's 'left-right' economic value orientation, which was administered in Waves 1, 3, 5, 7, 10, 14 and $17 .{ }^{27}$ Each measure has contrasting advantages and disadvantages. Party identification was measured in every wave and enables us to detect potential assimilation effects which are not based on changes in an individual's underlying preferences and beliefs, for example as a result of differences in the quality of candidates. By contrast, the left-right scale provides a finer-grained measure of political orientation, which enables detection of smaller changes across and within individuals over time and is not subject to the potentially distorting influence of tactical voting. Because of their differing theoretical and empirical properties we undertook all analyses using both measures of political preference. For the left-right scale, we took the first principal component of the six items, which is appropriate for these items. ${ }^{28}$ For party identification, we considered only supporters of the two main parties, Labour and the Conservatives. This yields a binary variable for party support which is considerably more straightforward to handle in a panel data regression framework than a nominal variable with more than two categories.

\section{Areal Units}

An important question in the study of contextual effects is how the areal units defining spatial location should be defined. The mechanisms through which contextual influence operates can manifest themselves at small (e.g. interaction with neighbours), intermediate (e.g. party mobilization in a constituency), or large (e.g. regional media) spatial scales. Studies of the influence of spatial scales on political behaviour have found, as in other substantive contexts, that choice of scale is consequential for the estimates obtained. ${ }^{29}$ In this study, we have used electoral constituencies as our areal units. Constituencies are the key electoral boundary in firstorder, parliamentary elections in the United Kingdom. In England, parliamentary constituencies contain an average of 70,000 voters, having approximately the population size of a small town. While interpersonal interactions with neighbours that might result in political assimilation happen at finer-grained levels of geography, the constituency level should still be capable of capturing local conditions and interactions in school and work-place settings that require some short-range mobility. Additionally, since party organizations work to win a majority of the vote within the constituency boundaries and constituencies share the same MP, the political environment within a constituency will probably be more internally homogeneous than the country as a whole.

Of more practical importance, however, is the fact that constituencies are the lowest geographical level at which it is possible to derive a useable measure of aggregate political

${ }^{26}$ That is, we consider it unlikely that political orientation is a strong determinant of drop-out from the study. Although the BHPS contains a longitudinal weight, using this to correct for differential attrition is not attractive because any unit with a single missing wave of data over the eighteen years of observation is dropped from the weighted estimator.

${ }^{27}$ Evans, Heath and Lalljee 1996; Heath, Evans and Martin 1994.

${ }^{28}$ Sturgis 2002.

${ }^{29}$ Cutts and Fieldhouse 2009; Johnston et al. 2007. 
orientation for the period in question. Electoral wards, which would be preferable with regard to size (they are smaller) are problematic because of the limited nature of information that can be attached to them and because their boundaries changed substantially between 1991 and 2008, rendering longitudinal analysis difficult. Other boundaries, such as census output areas, ${ }^{30}$ have no feasible way of being linked to electoral results or to other measures of aggregate political orientation. Thus, while our choice of areal unit is not perfect, we believe it to be the best amongst the available alternatives. We return to the implications of our use of constituencies as the areal unit for the interpretation of our findings in the discussion section.

While English constituency boundaries were quite stable in the period between 1991 and 2008, the redistricting for the 1997 general election affected a non-trivial number of constituency boundaries. However, most of the boundary changes affected only a small number of electors and the results we present here are robust to excluding observations located in constituencies which were subject to boundary changes during the reference period. ${ }^{31}$

\section{Area-Level Political Orientation}

We focus on the political orientation of the constituency as the main independent variable at the contextual level. Our measure is based on the electoral results for the four parliamentary elections held in 1992, 1997, 2001 and 2005. An intuitively appealing strategy would be to define constituency-level political orientation as the ratio (or similar function) of the vote share of the two main parties. However, this is challenging because of the sometimes significant role of tactical voting and of minor parties, which vary across constituencies and elections. Neither would it be clear how to apply vote shares to constituencies in non-election years. Therefore, we applied a typology to constituencies, placing them into one of six mutually exclusive categories: ${ }^{32}$

- Safe Conservative constituencies $(N=154)$ : The Conservative party won a parliamentary seat in all four elections.

- Safe Labour constituencies $(N=211)$ : The Labour party won a parliamentary seat in all four elections.

- Marginal Conservative constituencies $(N=12)$ : The Conservative party won a parliamentary seat in three of the four elections.

- Marginal Labour constituencies $(N=111)$ : The Labour party won a parliamentary seat in three of the four elections.

- Safe or marginal Liberal-Democrat constituencies $(N=31)$ : The Liberal-Democratic party won a parliamentary seat in three or four elections.

- Mixed constituencies $(N=47)$ : None of the three main parties won a seat in three or four of the elections.

30 Martin 2008.

31 Constituency identifiers in the BHPS are over-written with the new constituency code when boundaries change. This means that it is not possible to identify which respondents in our analysis sample changed to a different constituency without moving house due to the 1997 boundary revisions. However, we are able to identify respondents who are resident in constituencies which were created in 1997 and therefore we can estimate models including and excluding this group. We find no significant differences in the patterns reported in the analyses.

${ }^{32}$ In case of boundary revision, the coding matches any constituency revised in 1997 to the 1992 constituency with which it has the largest overlap (see Norris 2005). 
During the period of analysis, parties other than the main three won a parliamentary seat once in eight constituencies, ${ }^{33}$ and only in one constituency did a different party win two elections. The mixed category is mostly made up of constituencies in which one of the three large parties won two elections and another of the large parties won the other two elections. Thus, these are the most competitive constituencies, where no party has a clear dominance. This classification of constituencies captures large differences in voting patterns. For instance, in the 1992 election the Conservative party won on average 57 per cent of the vote in safe Conservative seats but only 33 per cent in safe Labour seats. The Labour party received 18 per cent of the vote in safe Conservative seats and 53 per cent in safe Labour seats.

\section{Residential Mobility}

In our analysis sample, we observed a total of 14,500 residential moves from one wave to the next, which represents an average annual move rate of just over 9 per cent across the sample as a whole. Many of these relocations are, however, over a small distance within the same constituency and so would not be expected to result in discernible change in the external political environment. Therefore, we further restricted our definition of 'movers' to individuals who relocated to a different parliamentary constituency. This reduced the number of moves we observe by approximately half, yielding a total of 7,437. Using this definition, 69 per cent of respondents did not move at all, 17.5 per cent moved once, 7 per cent moved twice and 6.5 per cent moved three times or more during the period of observation. ${ }^{34}$

Table 1 shows one-year transition probabilities (as percentages) for moves between different constituency types. Only individuals who were observed in at least two consecutive waves can be included in transition tables, which results in a reduction of the sample size from 142,000 to 125,000 observations. ${ }^{35}$ The diagonal row in Table 2 comprises observations which remained in the same constituency type in any two-year period. The majority of observations did not move into different constituency types. However, of the 36,900 observations in safe Conservative constituencies, 315 moved into safe Labour constituencies in a subsequent year. Similarly, of the 41,100 observations in safe Labour constituencies, 417 moved to a safe Conservative constituency in a subsequent year. Of the 28,000 observations in marginal Labour constituencies, approximately 400 moved to safe Labour and safe Conservative constituencies respectively.

Because the inclusion of the full set of transition probabilities results in categories with small cell sizes we collapsed the full set of transitions into the following six categories:

1. No move

2. Moves from any constituency type (apart from safe Conservative) into safe Conservative

3. Moves from any constituency type (apart from safe Labour) into safe Labour

\footnotetext{
33 These are: Bethnal Green and Bow, Birmingham Sparkbrook and Small Heath, Brentwood and Ongar, East Ham, Staffordshire South, Tatton, West Bromwich West, West Ham.

${ }^{34}$ While the United States is widely considered to have high rates of residential mobility, one-year mobility rates are similar to those observed in Britain; 12 per cent of the US population moved to a different address in 2005, while 11 per cent of the population in Britain did so (Molloy, Smith and Wozniak 2011). Data from the 2001 Census and administrative records suggest that about 6.7 million UK residents, or 11.4 per cent of the population, moved from one address to another in the previous twelve months (Champion 2005). Most of these moves are over short distances, with approximately two fifths moving less than $2 \mathrm{~km}$ away and only one third moving more than $10 \mathrm{~km}$ away.

35 All observations in the first wave (1991) of the BHPS do not have earlier information and can, therefore, not be used. Individuals who drop out of waves cannot provide transition information.
} 


\begin{tabular}{lccccccc}
\hline \hline & \multicolumn{7}{c}{ Time period, $t_{+1}$} \\
\cline { 2 - 8 } Time period, $t$ & Safe Con. & Safe Lab. & Safe Lib. & Marg. Con. & Marg. Lab. & Mixed & Total \\
\hline Safe Con. & 35,985 & 315 & 105 & 32 & 303 & 196 & 36,936 \\
& 97.43 & 0.85 & 0.28 & 0.09 & 0.82 & 0.53 & 100 \\
Safe Lab. & 417 & 39,969 & 104 & 32 & 505 & 124 & 41,151 \\
& 1.01 & 97.13 & 0.25 & 0.08 & 1.23 & 0.30 & 100 \\
Safe Lib. & 123 & 91 & 5,531 & 3 & 59 & 33 & 5,840 \\
& 2.11 & 1.56 & 94.71 & 0.05 & 1.01 & 0.57 & 100 \\
Marg. Con. & 38 & 17 & 3 & 1,543 & 15 & 9 & 1,625 \\
& 2.34 & 1.05 & 0.18 & 94.95 & 0.92 & 0.55 & 100 \\
Marg. Lab. & 437 & 483 & 83 & 20 & 26,756 & 125 & 27,904 \\
& 1.57 & 1.73 & 0.30 & 0.07 & 95.89 & 0.45 & 100 \\
Mixed & 174 & 113 & 38 & 13 & 141 & 11,083 & 11,562 \\
& 1.50 & 0.98 & 0.33 & 0.11 & 1.22 & 95.86 & 100 \\
Total & 37,174 & 40,988 & 5,864 & 1,643 & 27,779 & 11,570 & 125,018 \\
& 29.73 & 32.79 & 4.69 & 1.31 & 22.22 & 9.25 & 100 \\
\hline \hline
\end{tabular}

Source: BHPS 1991-2008.

Note: The table shows the total number of moves over all transition pair-years and, below these, the average percentage of respondents transitioning in such pair-years.

4. Moves from safe Conservative into safe Conservative

5. Moves from safe Labour into safe Labour

6. All other move types.

It is moves of Types 2 and 3 which are of greatest analytical interest because they represent a clear change in the political orientation of the area in which an individual lives. ${ }^{36}$ They can be considered, therefore, as ideal test-cases for theories of contextual effects. We focus our attention on these two move types in the analyses that follow, although analyses have been undertaken for all move types and will be made available upon request.

\section{METHOD}

To estimate the effect on individual political preferences of people moving to an area with a different political context, we use a panel data model with fixed effects and distributed lags and leads. ${ }^{37}$ We include lagged effects because the influence of a new area on a mover is unlikely to occur immediately, potentially taking several years or more to materialize. The baseline model has the following form:

$$
y_{i t}=\sum_{k=0}^{5} \operatorname{MovCon}_{i, t-k}^{\prime} \beta_{-k}+x_{i t}^{\prime} \lambda+e_{i t}
$$

where the political preferences of the $i$-th person in the $t$-th year, $y_{i t}$, are modelled as depending on the type of move in the preceding five years, $\mathbf{M o v C o n}_{i, t-k}{ }^{\prime}$, a design vector corresponding to

\footnotetext{
${ }^{36}$ In principle moves from safe Conservative to safe Labour constituencies and vice versa are of greatest theoretical interest, although our sample size is insufficient to go to this level of granularity.

37 Blanden et al. 2012; Laporte and Windmeijer 2005.
} 
the six categories of move type described in the previous section, and 'no move' as the reference category. Time-varying covariates are collected in the vector $\boldsymbol{x}_{i t}$. At the individual level we control for sex, age, age squared, educational level, income, social class, employment status, health status, marital status, and parental status. Where models are estimated with fixed effects, time-invariant characteristics such as sex are excluded. To control for spurious effects caused by unobserved differences between individuals that are time-invariant, each person's observations are centred on the within-person mean. That is, we use time-demeaned data such that an individual's score at time $t$ is subtracted from their person specific mean over all observations across all time points $\left(y_{i t}=\tilde{y}_{i t}-\overline{\bar{y}}_{i}\right)$. The well-known consequence of using time-demeaned data is that all time-invariant characteristics of sample units are 'differenced out', yielding the fixed effects model.

The coefficients of primary interest in Equation 1 are the lagged coefficient vectors $\boldsymbol{\beta}_{-k}$ where $\mathrm{k}$ is set to a maximum of 5 . The choice of a five-year maximum lag is a trade-off between our theoretical expectation that it may take several years for a contextual effect to be manifested and the fact that extending lags beyond five years results in small cell sizes and, therefore, imprecise estimates. Moreover, as we shall show later, increasing the number of lags to nine years does not alter our key substantive findings. One way of thinking about how to interpret the lagged coefficients is to consider a hypothetical person who moves to a safe Labour constituency one year but then moves back the next year: $\boldsymbol{\beta}_{-k}$, labour will then be the effect on political preferences of that one-time move after $k$ years, controlling for time-invariant unobserved variables and time-varying covariates. However, people typically stay in their new place of residence for longer than one year, so it is also of interest to know what the effect of the move on preferences will be when the effect is aggregated over ensuing years. This 'long-run effect' can be obtained by summing the coefficients over the lag vector:

$$
\boldsymbol{\beta}_{\text {long-run }}=\sum_{k=0}^{5} \boldsymbol{\beta}_{-k}
$$

Hypothesis tests of zero long-run effects can be performed by obtaining the sampling variance of $\hat{\boldsymbol{\beta}}_{\text {long-run }}$, which by standard methods, can be shown to be:

$$
\operatorname{var}\left(\hat{\boldsymbol{\beta}}_{\text {long-run }}\right)=\sum_{k=0}^{5} \operatorname{var}\left(\hat{\boldsymbol{\beta}}_{-k}\right)+2 \sum_{k<l} \operatorname{cov}\left(\hat{\boldsymbol{\beta}}_{-k}, \hat{\boldsymbol{\beta}}_{-l}\right)
$$

Note that this means that individual hypothesis tests performed on the lagged effects $\boldsymbol{\beta}_{-k}$ may be non-significant while the overall hypothesis test on $\boldsymbol{\beta}_{\text {long-run }}$ is significantly greater than 0 .

By using a fixed effects model with time-varying covariates, we control for possible confounding due to unobserved between-person differences, as well as observed differences due to the covariates. Although this is already a strong research design, confounding could conceivably still occur if the probability of moving is correlated with the propensity to change political preferences. For example, becoming a parent is an event that can cause both a residential move and a change in political preferences. Blanden et al. propose controlling for the effect of such 'pre-programme trends' by including 'lead' dummies in the model. ${ }^{38}$ The coefficients for the effect of the future on the present, $\boldsymbol{\gamma}_{+k}$, should not be interpreted causally, but as evidence for selection effects on the change in preferences. By including leads in the model, our final specification becomes:

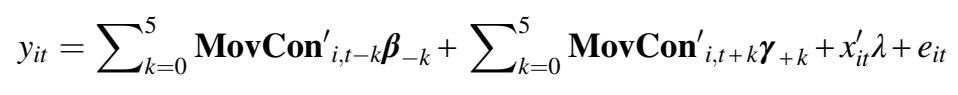

38 Blanden et al. 2012. 
In addition to their substantive interpretation as indicators of political selection into areas, the inclusion of leads also enables us to obtain estimates of the lagged effects, adjusted for nonrandom selection into areas. Thus, our control for time-constant, time-varying, as well as trend selection effects motivates the interpretation of the lagged coefficients $\boldsymbol{\beta}_{-\boldsymbol{k}}$ and their long-run versions $\boldsymbol{\beta}_{\text {long-run }}$ as the effect of the constituency on an individual's political preferences. Finally, it should be noted that the use of lags and leads in their raw form results in reduced sample size. This is because for some observations, we do not observe political preferences five years before and after a move. Rather than dropping such observations we set the unobserved prior and subsequent moves to 0 and include a vector of dummies representing 'missingness' in the model, although we do not report the coefficient estimates in our results. Specification tests show that our findings are substantively unaffected by the inclusion or exclusion of these cases.

\section{RESULTS}

We begin by presenting some descriptive statistics before moving to more causally-focused analyses. An implication of contextual theories of political behaviour is that the magnitude of an assimilation effect should (initially at least) increase over time, because the opportunity for and experience of the various influence mechanisms will grow as a function of time spent in a locale. ${ }^{39}$ Thus, we should expect the association between constituency type and individual policy preferences to increase over the number of years an individual has lived in the area. Figure 1 shows percentage support for the Conservative party and the mean of the left-right scale by type of constituency and the number of years the individual has lived at their current address. ${ }^{40}$

Individuals who live in safe Conservative constituencies are likely to support the Conservative party even immediately after moving to their new place of residence. Additionally, the longer the period of residence within a safe Conservative constituency, the more likely an individual is to support the Conservatives. Conversely, individuals in safe Labour constituencies, while considerably more likely to support the Labour party, show no trend towards increasing support for Labour the longer they have lived in a safe Labour constituency. This may be due, partially at least, to a ceiling effect because the level of support for Labour in safe Labour constituencies is already close to 75 per cent at year zero. The pattern for the left-right scale is clearer and more consistent, with individuals in safe Conservative constituencies expressing more right-wing views the longer they have lived in that area and the opposite being the case for individuals in safe Labour constituencies. Thus, the BHPS provides quite strong preliminary evidence of contextual effects; people are closer to the aggregate political orientation of their constituency the longer they have lived in it. However, although Figure 1 shows an apparent trend over time, the data is analysed cross-sectionally and the variation is, therefore, between rather than within individuals. Thus, the patterns we observe may have emerged due to non-random selection of individuals into (and out of) areas rather than to the effect of areas on individuals. It is to this possibility that we now turn via regression analysis.

Table 2 presents the results of our regression models for the left-right value scale and party support over ten columns, with each column representing a different model specification.

39 A corollary example is the long-established association between the political preferences of married and co-habiting couples. Alford et al. (2011) argue that, if the intra-spousal correlation is due to influence rather than self-selection, we should observe partners becoming more similar to each other the longer they are together.

40 The 'time lived in constituency' variable is derived from the address record rather than by self-report. We limit the upper bound of time at address to ten years because 'time at address' is increasingly confounded with age as 'time at residence' increases. 


\begin{tabular}{|c|c|c|c|c|c|c|c|c|c|c|}
\hline \multirow[b]{2}{*}{ Move type, and timing $\dagger$} & \multicolumn{5}{|c|}{ Left-right score } & \multicolumn{5}{|c|}{ Supports Conservative party } \\
\hline & (1) & $(2)$ & (3) & (4) & $(5)$ & (6) & (7) & $(8)$ & (9) & $(10)$ \\
\hline \multicolumn{11}{|c|}{ Leads, from any to safe Conservative } \\
\hline $\mathrm{t}_{+5}, 5 \mathrm{yrs}$ after & & $\begin{array}{c}0.191 * \\
(0.095)\end{array}$ & & & $\begin{array}{c}-0.011 \\
(0.064)\end{array}$ & & $\begin{array}{l}1.467 * * * \\
(0.160)\end{array}$ & & & $\begin{array}{c}1.353 \\
(0.430)\end{array}$ \\
\hline $\mathrm{t}_{+4}, 4 \mathrm{yrs}$ after & & $\begin{array}{c}0.188^{*} \\
(0.089)\end{array}$ & & & $\begin{array}{c}-0.016 \\
(0.058)\end{array}$ & & $\begin{array}{l}1.675^{* * * *} \\
(0.169)\end{array}$ & & & $\begin{array}{l}1.319 \\
(0.376)\end{array}$ \\
\hline $\mathrm{t}_{+3}, 3 \mathrm{yrs}$ after & & $\begin{array}{c}0.166^{*} \\
(0.078)\end{array}$ & & & $\begin{array}{c}-0.078 \\
(0.056)\end{array}$ & & $\begin{array}{l}1.414 * * * \\
(0.133)\end{array}$ & & & $\begin{array}{l}1.114 \\
(0.282)\end{array}$ \\
\hline $\mathrm{t}_{+2}, 2 \mathrm{yrs}$ after & & $\begin{array}{c}0.153^{*} \\
(0.070)\end{array}$ & & & $\begin{array}{c}-0.049 \\
(0.055)\end{array}$ & & $\begin{array}{l}1.499 * * * \\
(0.130)\end{array}$ & & & $\begin{array}{c}0.967 \\
(0.249)\end{array}$ \\
\hline $\mathrm{t}_{+1}, 1 \mathrm{yr}$ after & & $\begin{array}{c}0.051 \\
(0.070)\end{array}$ & & & $\begin{array}{c}-0.024 \\
(0.052)\end{array}$ & & $\begin{array}{l}1.297 * * \\
(0.105)\end{array}$ & & & $\begin{array}{l}1.166 \\
(0.286)\end{array}$ \\
\hline \multicolumn{11}{|c|}{ Contemporaneous move, from any to safe Conservative } \\
\hline $\mathrm{t}_{0}, \mathrm{yr}$ of move & $\begin{array}{l}0.253^{* * *} \\
(0.075)\end{array}$ & $\begin{array}{l}0.230^{* *} \\
(0.075)\end{array}$ & $\begin{array}{l}0.206^{* *} \\
(0.074)\end{array}$ & $\begin{array}{c}0.047 \\
(0.051)\end{array}$ & $\begin{array}{c}0.035 \\
(0.053)\end{array}$ & $\begin{array}{l}1.521 * * * \\
(0.123)\end{array}$ & $\begin{array}{l}1.456 * * * \\
(0.120)\end{array}$ & $\begin{array}{l}1.593 * * * \\
(0.139)\end{array}$ & $\begin{array}{l}1.114 \\
(0.258)\end{array}$ & $\begin{array}{c}1.124 \\
(0.281)\end{array}$ \\
\hline \multicolumn{11}{|c|}{ Lags, from any to safe Conservative } \\
\hline $\mathrm{t}_{-1}, 1 \mathrm{yr}$ before & $\begin{array}{c}0.159 * \\
(0.084)\end{array}$ & $\begin{array}{c}0.130 \\
(0.083)\end{array}$ & $\begin{array}{c}0.147 \\
(0.083)\end{array}$ & $\begin{array}{c}0.085 \\
(0.054)\end{array}$ & $\begin{array}{c}0.065 \\
(0.057)\end{array}$ & $\begin{array}{l}1.414 * * * \\
(0.120)\end{array}$ & $\begin{array}{l}1.354 * * * \\
(0.117)\end{array}$ & $\begin{array}{l}1.471 * * * \\
(0.136)\end{array}$ & $\begin{array}{c}1.047 \\
(0.246)\end{array}$ & $\begin{array}{c}1.080 \\
(0.269)\end{array}$ \\
\hline $\mathrm{t}_{-2}, 2$ yrs before & $\begin{array}{c}0.156^{*} \\
(0.079)\end{array}$ & $\begin{array}{c}0.129 \\
(0.079)\end{array}$ & $\begin{array}{c}0.107 \\
(0.076)\end{array}$ & $\begin{array}{c}0.020 \\
(0.057)\end{array}$ & $\begin{array}{c}-0.001 \\
(0.059)\end{array}$ & $\begin{array}{l}1.329 * * \\
(0.120)\end{array}$ & $\begin{array}{l}1.285^{* *} \\
(0.118)\end{array}$ & $\begin{array}{l}1.380^{* *} \\
(0.138)\end{array}$ & $\begin{array}{c}0.744 \\
(0.190)\end{array}$ & $\begin{array}{c}0.750 \\
(0.200)\end{array}$ \\
\hline $\mathrm{t}_{-3}, 3$ yrs before & $\begin{array}{c}0.207^{*} \\
(0.089)\end{array}$ & $\begin{array}{c}0.190^{*} \\
(0.088)\end{array}$ & $\begin{array}{l}0.133 \\
(0.085)\end{array}$ & $\begin{array}{c}0.139^{*} \\
(0.059)\end{array}$ & $\begin{array}{l}0.130 * \\
(0.061)\end{array}$ & $\begin{array}{l}1.235^{*} \\
(0.117)\end{array}$ & $\begin{array}{l}1.209^{*} \\
(0.117)\end{array}$ & $\begin{array}{l}1.198 \\
(0.124)\end{array}$ & $\begin{array}{l}0.865 \\
(0.226)\end{array}$ & $\begin{array}{c}0.899 \\
(0.243)\end{array}$ \\
\hline $\mathrm{t}_{-4,4}$ yrs before & $\begin{array}{c}0.176 \\
(0.095)\end{array}$ & $\begin{array}{c}0.173 \\
(0.096)\end{array}$ & $\begin{array}{c}0.115 \\
(0.091)\end{array}$ & $\begin{array}{c}0.045 \\
(0.065)\end{array}$ & $\begin{array}{c}0.025 \\
(0.067)\end{array}$ & $\begin{array}{l}1.206 \\
(0.122)\end{array}$ & $\begin{array}{l}1.185 \\
(0.122)\end{array}$ & $\begin{array}{l}1.271^{*} \\
(0.143)\end{array}$ & $\begin{array}{c}0.620 \\
(0.164)\end{array}$ & $\begin{array}{c}0.654 \\
(0.179)\end{array}$ \\
\hline $\mathrm{t}_{-5}, 5 \mathrm{yrs}$ before & $\begin{array}{c}-0.001 \\
(0.098)\end{array}$ & $\begin{array}{c}-0.007 \\
(0.098)\end{array}$ & $\begin{array}{c}-0.050 \\
(0.091)\end{array}$ & $\begin{array}{l}0.088 \\
(0.066)\end{array}$ & $\begin{array}{c}0.073 \\
(0.068)\end{array}$ & $\begin{array}{l}1.197 \\
(0.120)\end{array}$ & $\begin{array}{l}1.180 \\
(0.120)\end{array}$ & $\begin{array}{l}1.250^{*} \\
(0.135)\end{array}$ & $\begin{array}{c}0.821 \\
(0.215)\end{array}$ & $\begin{array}{c}0.843 \\
(0.228)\end{array}$ \\
\hline \multicolumn{11}{|c|}{ Leads, from any to safe Labour } \\
\hline \multicolumn{2}{|c|}{$t_{+5}, 5$ yrs after } & $\begin{array}{c}-0.056 \\
(0.105)\end{array}$ & & & $\begin{array}{c}0.108 \\
(0.080)\end{array}$ & & $\begin{array}{l}0.840 \\
(0.105)\end{array}$ & & & $\begin{array}{c}0.765 \\
(0.261)\end{array}$ \\
\hline $\mathrm{t}_{+4}, 4 \mathrm{yrs}$ after & & $\begin{array}{c}0.071 \\
(0.093)\end{array}$ & & & $\begin{array}{l}0.066 \\
(0.065)\end{array}$ & & $\begin{array}{l}0.723 * * \\
(0.088)\end{array}$ & & & $\begin{array}{c}0.656 \\
(0.229)\end{array}$ \\
\hline $\mathrm{t}_{+3}, 3$ yrs after & & $\begin{array}{c}-0.127 \\
(0.089)\end{array}$ & & & $\begin{array}{c}-0.060 \\
(0.068)\end{array}$ & & $\begin{array}{l}0.871 \\
(0.095)\end{array}$ & & & $\begin{array}{c}0.954 \\
(0.315)\end{array}$ \\
\hline $\mathrm{t}_{+2}, 2 \mathrm{yrs}$ after & & $\begin{array}{c}-0.086 \\
(0.081)\end{array}$ & & & $\begin{array}{l}-0.166^{* *} \\
(0.063)\end{array}$ & & $\begin{array}{c}0.869 \\
(0.089)\end{array}$ & & & $\begin{array}{c}0.770 \\
(0.251)\end{array}$ \\
\hline $\mathrm{t}_{+1}, 1 \mathrm{yr}$ after & & $\begin{array}{c}-0.065 \\
(0.070)\end{array}$ & & & $\begin{array}{c}-0.022 \\
(0.059)\end{array}$ & & $\begin{array}{c}0.912 \\
(0.085)\end{array}$ & & & $\begin{array}{l}1.116 \\
(0.328)\end{array}$ \\
\hline
\end{tabular}


Contemporaneous, from any to safe Labour

\begin{tabular}{|c|c|c|c|c|c|c|c|c|c|c|}
\hline $\mathrm{t}_{0}, \mathrm{yr}$ of move & $\begin{array}{l}-0.025 \\
(0.083)\end{array}$ & $\begin{array}{c}-0.004 \\
(0.082)\end{array}$ & $\begin{array}{l}0.045 \\
(0.080)\end{array}$ & $\begin{array}{l}-0.003 \\
(0.059)\end{array}$ & $\begin{array}{c}-0.022 \\
(0.062)\end{array}$ & $\begin{array}{c}0.870 \\
(0.083)\end{array}$ & $\begin{array}{c}0.930 \\
(0.091)\end{array}$ & $\begin{array}{c}1.071 \\
(0.109)\end{array}$ & $\begin{array}{c}1.376 \\
(0.393)\end{array}$ & $\begin{array}{r}1.323 \\
(0.403\end{array}$ \\
\hline \multicolumn{11}{|c|}{ Lags, from any to safe Labour } \\
\hline $\mathrm{t}_{-1}, 1$ yrs before & $\begin{array}{c}-0.102 \\
(0.089)\end{array}$ & $\begin{array}{c}-0.078 \\
(0.088)\end{array}$ & $\begin{array}{l}-0.056 \\
(0.086)\end{array}$ & $\begin{array}{c}0.006 \\
(0.062)\end{array}$ & $\begin{array}{c}-0.017 \\
(0.065)\end{array}$ & $\begin{array}{c}0.924 \\
(0.093)\end{array}$ & $\begin{array}{c}0.959 \\
(0.096)\end{array}$ & $\begin{array}{c}1.091 \\
(0.117)\end{array}$ & $\begin{array}{c}0.927 \\
(0.267)\end{array}$ & $\begin{array}{r}0.863 \\
(0.265\end{array}$ \\
\hline \multirow[t]{2}{*}{$\mathrm{t}_{-2}, 2$ yrs before } & -0.017 & -0.014 & 0.011 & 0.004 & -0.014 & 0.861 & 0.875 & 1.005 & 0.994 & 0.970 \\
\hline & $(0.098)$ & $(0.098)$ & $(0.097)$ & $(0.067)$ & $(0.070)$ & $(0.092)$ & $(0.094)$ & $(0.118)$ & $(0.301)$ & $(0.310$ \\
\hline $\mathrm{t}_{-3}, 3$ yrs before & $\begin{array}{c}0.063 \\
(0.093)\end{array}$ & $\begin{array}{c}0.062 \\
(0.094)\end{array}$ & $\begin{array}{c}0.071 \\
(0.092)\end{array}$ & $\begin{array}{c}0.040 \\
(0.067)\end{array}$ & $\begin{array}{c}0.029 \\
(0.070)\end{array}$ & $\begin{array}{c}0.857 \\
(0.097)\end{array}$ & $\begin{array}{c}0.864 \\
(0.098)\end{array}$ & $\begin{array}{l}1.040 \\
(0.125)\end{array}$ & $\begin{array}{c}0.891 \\
(0.270)\end{array}$ & $\begin{array}{r}0.866 \\
(0.275\end{array}$ \\
\hline $\mathrm{t}_{-4}, 4$ yrs before & $\begin{array}{c}-0.159 \\
(0.107)\end{array}$ & $\begin{array}{c}-0.159 \\
(0.106)\end{array}$ & $\begin{array}{l}-0.155 \\
(0.107)\end{array}$ & $\begin{array}{l}-0.201 * * \\
(0.078)\end{array}$ & $\begin{array}{l}-0.216^{* *} \\
(0.080)\end{array}$ & $\begin{array}{c}0.790 \\
(0.097)\end{array}$ & $\begin{array}{c}0.793 \\
(0.099)\end{array}$ & 0.789 & 0.568 & $\begin{array}{r}0.538 \\
0.192\end{array}$ \\
\hline $\mathrm{t}_{-5,5}$ yrs before & $\begin{array}{c}-0.034 \\
(0.117)\end{array}$ & $\begin{array}{c}-0.1017 \\
(0.118)\end{array}$ & $\begin{array}{c}-0.004 \\
(0.118)\end{array}$ & $\begin{array}{l}-0.046 \\
(0.078)\end{array}$ & $\begin{array}{c}-0.071 \\
(0.081)\end{array}$ & $\begin{array}{c}0.958 \\
(0.124)\end{array}$ & $\begin{array}{c}0.960 \\
(0.126)\end{array}$ & $\begin{array}{l}1.107 \\
(0.154)\end{array}$ & $\begin{array}{c}0.184 \\
(0.264)\end{array}$ & $\begin{array}{r}0.764 \\
(0.271\end{array}$ \\
\hline Other move types & yes & yes & yes & yes & yes & yes & yes & no & no & no \\
\hline Individual controls & no & no & yes & yes & yes & no & no & no & no & no \\
\hline Individual fixed effects & no & no & no & yes & yes & no & no & no & no & no \\
\hline Leads & no & yes & no & no & yes & no & no & no & no & no \\
\hline \multirow[t]{2}{*}{ Constant } & $0.041^{*}$ & $0.088^{* * *}$ & $0.665^{* * *}$ & $0.222 *$ & $0.277 *$ & $-1.124 *$ & $0.830 * * *$ & $-0.808^{*}$ & $\mathrm{n} / \mathrm{a}$ & $\mathrm{n} / \mathrm{a}$ \\
\hline & $(0.017)$ & $(0.022)$ & $(0.133)$ & $(0.105)$ & $(0.108)$ & $(0.260)$ & $(0.019)$ & $(0.200)$ & $\mathrm{n} / \mathrm{a}$ & $\mathrm{n} / \mathrm{a}$ \\
\hline \multicolumn{11}{|c|}{ Long-run multiplier effects (lags) } \\
\hline \multicolumn{2}{|c|}{ Any to safe Con $0.945^{* * *}$} & $\begin{array}{l}0.845^{* *} \\
(0.283)\end{array}$ & $\begin{array}{l}0.639 * * \\
(0.268)\end{array}$ & $\begin{array}{l}0.428 * \\
(0.167)\end{array}$ & $\begin{array}{c}0.326 \\
(0.188)\end{array}$ & $\begin{array}{l}5.092 * * * \\
(2.297)\end{array}$ & $\begin{array}{l}4.282 * * \\
(1.973)\end{array}$ & $\begin{array}{l}6.154 * * * \\
(2.896)\end{array}$ & $\begin{array}{c}0.382 \\
(0.296)\end{array}$ & $\begin{array}{r}0.451 \\
(0.402\end{array}$ \\
\hline $\begin{array}{l}\left(\mathrm{t}_{0}+\mathrm{t}_{1}+\mathrm{t}_{2}+\mathrm{t}_{3}+\mathrm{t}_{4}+\mathrm{t}_{5}\right) \\
\text { Any to safe } \mathrm{Lab}\end{array}$ & -0.274 & -0.211 & -0.088 & -0.200 & -0.120 & 0.449 & 0.513 & 1.066 & 0.502 & $\begin{array}{r}(0.402 \\
0.394\end{array}$ \\
\hline \multirow{2}{*}{$N$} & $(0.303)$ & $(0.303)$ & $(0.302)$ & $(0.197)$ & $(0.227)$ & $(0.238)$ & $(0.275)$ & $(0.585)$ & $(0.500)$ & $(0.450$ \\
\hline & 49,105 & 49,105 & 48,974 & 48,974 & 48,974 & 78,573 & 78,573 & 72,979 & 15,542 & 15,54 \\
\hline
\end{tabular}

Notes: Cluster standard errors in parentheses. Additional move types include Safe Con to Safe Con, Safe Lab to Safe Lab and Other Mover Types. Individual controls include: age, gender, education, marital status, children, income, class status, employment status, part/full-time, health status and time dummies. Coefficients in Models 1 to 5 are ordinary least squares, in Models 6 to 10 coefficients are odds ratios. Note that the long-run multiplier for Models 6 to 10 is derived by summing the exponentiated logit coefficients and converting this to odds ratios rather than summing the individual odds ratios. $* p<0.05, * * p<0.01, * * * p<0.001$.

$\dagger$ Reference group consists of those who have not moved. 

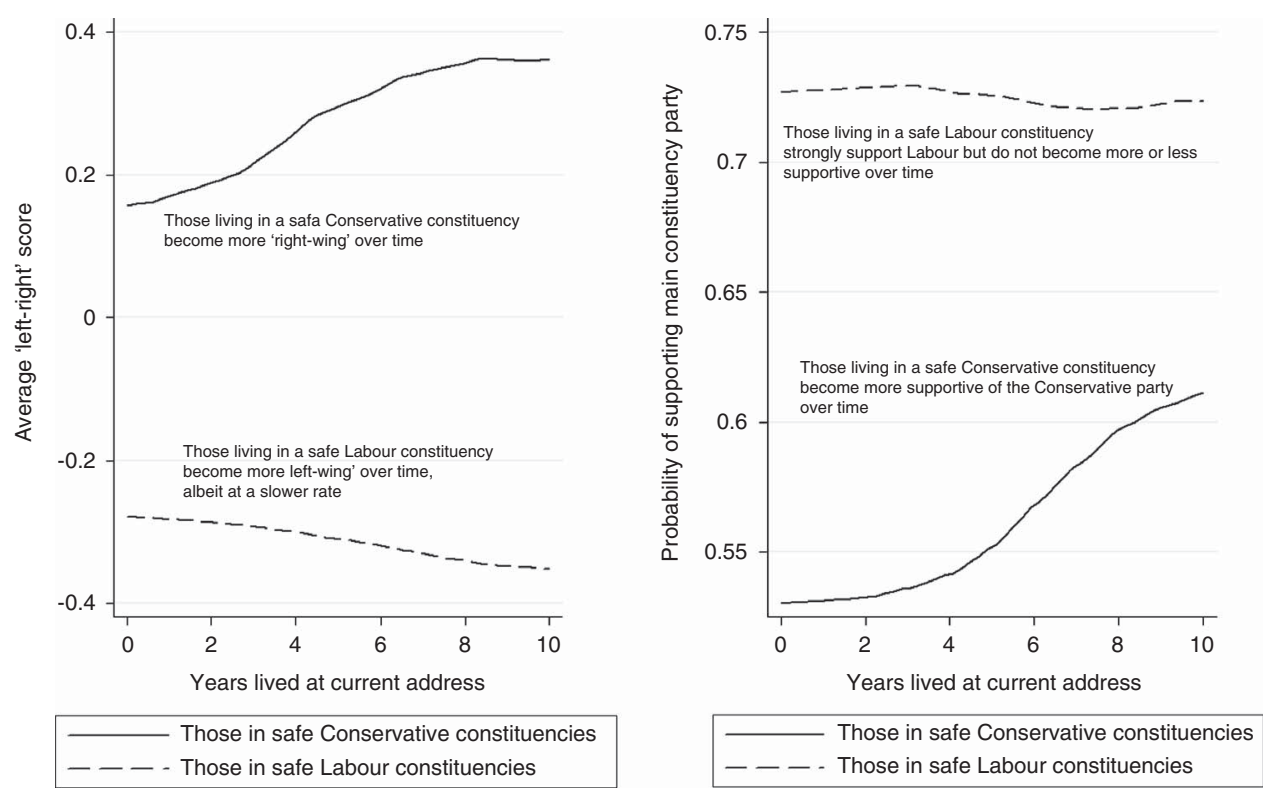

Fig. 1. Party identification and left-right economic values over time lived in constituency

In Model 1 we include only lags, no individual-level controls and no fixed effects. Model 2 adds leads to this specification. Model 3 contains lags and individual level controls but no leads or fixed effects, whilst Model 4 introduces individual fixed effects to Model 3. Finally, Model 5 reintroduces lead indicators. The same pattern is repeated for party support in Models 6 to 10, though now we use a logistic link function because the outcome is binary. In Table 2 we suppress the results for other move types (such as moving from a safe Conservative constituency to another safe Conservative constituency) and for the control variables. ${ }^{41}$ The results of these additional contrasts make no material difference to our substantive conclusions. In all models the reference category for the different move types is non-movers. Thus the coefficients should be interpreted as the effect of making the move type in question on political preferences, compared to (covariate adjusted) non-movers.

Model 1 in Table 2 shows that moving into a safe Conservative constituency from any other type of constituency is associated with a significant move to the right on the left-right scale (higher scores indicate more right-wing preferences). The long-run multiplier for this move type is $0.946(p<0.001)$, indicating significant and quite substantial contextual effects over the five years following the move. The magnitude of this effect is approximately equivalent to the average cross-sectional difference in left-right scores between a Liberal Democrat and a Conservative party identifier. The negative coefficients for the effect of moving into a safe Labour constituency from other constituency types provides some evidence of assimilation for this type of move, though none of these is statistically significant, either singly or in combination. This pattern corresponds to that which was observed for the cross-sectional analysis in Figure 1, where the trend for Conservative support was stronger than for Labour support.

Model 2 introduces lead indicators. Significant coefficients for the lead dummies suggest that, before controlling for other characteristics, individuals behave as if they choose their new areas,

41 These results are available from the corresponding author upon request. 

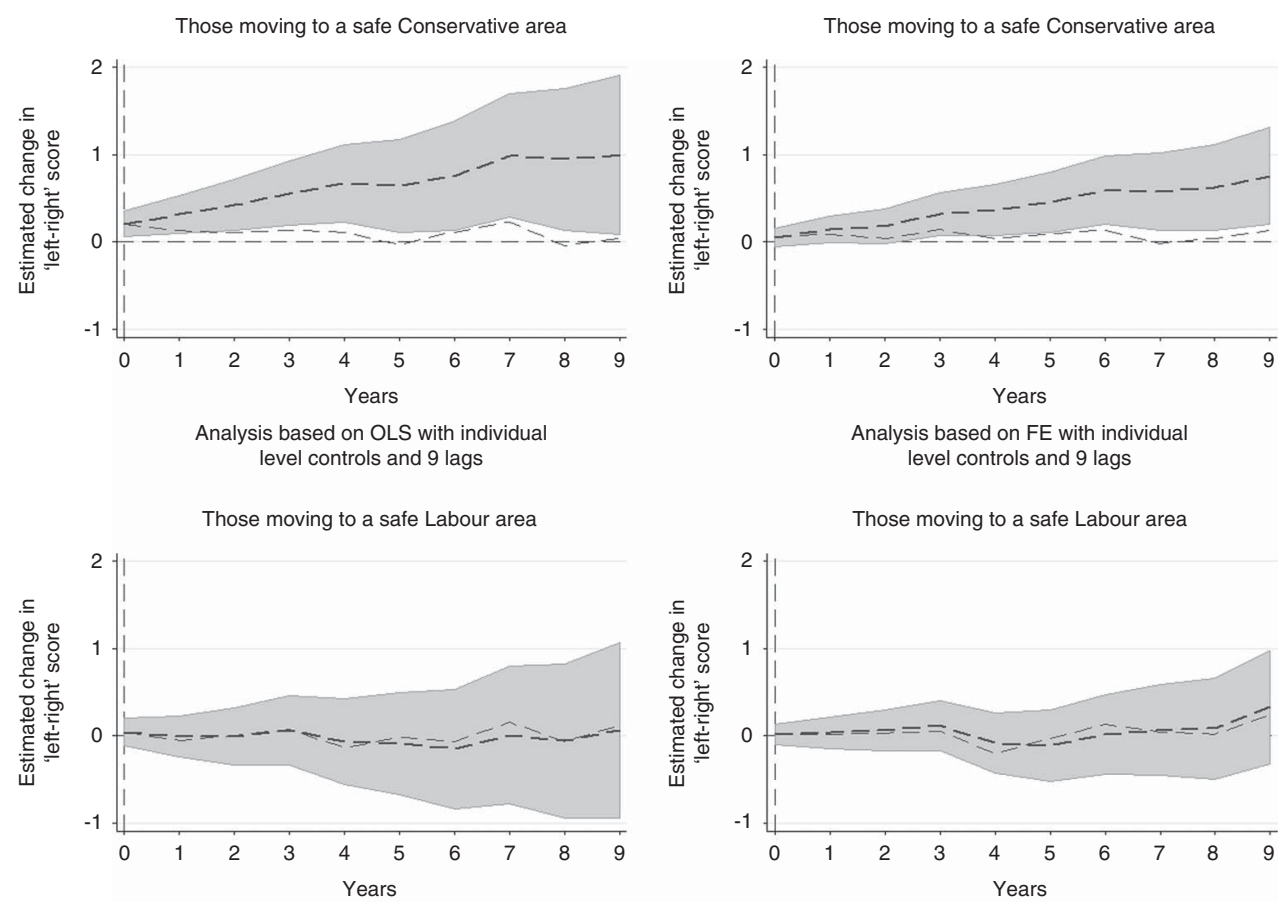

Analysis based on OLS with individual level controls and 9 lags

Analysis based on FE with individual level controls and 9 lags

95\% Cl

- - - - Yearly Impact

Fig. 2. Assimilation to left-right values by type of moves over time with extended lags

at least in part, on the basis of their prior political preferences. Our results suggest that those moving to safe Conservative areas become significantly more right-wing prior to a move. The coefficient estimates for those moving to safe Labour constituencies are not statistically significant, although they are of the correct sign (they become more left-wing). The long-run multiplier for those moving to safe Conservative areas between time period 0 and time period 5 has been reduced slightly to $0.845(p<0.003)$, indicating smaller, but still substantial, assimilation effects after controlling for non-random selection into constituency types. However, these estimates cannot be considered causal as we have not yet controlled for selection on observed time-varying and time-invariant characteristics.

In Model 3, we remove the lead dummies and introduce individual level controls for characteristics which might lead people to relocate to a different constituency and also to change their political orientation. These are: age, gender, marital status, parental status, household income, social class, employment status and health status. We also include year dummies to control for macro-level events in the external environment. Introduction of these controls results in the lagged coefficients becoming somewhat reduced in magnitude, which suggests that the assimilation effects observed in Model 1 are at least partly due to non-random selection of individuals into constituencies. Controlling for these individual characteristics and survey year reduces the long-run multiplier to 0.639 , which although statistically significant $(p<0.018)$, represents a 30 per cent reduction in magnitude compared to Model 1. Estimates for those 

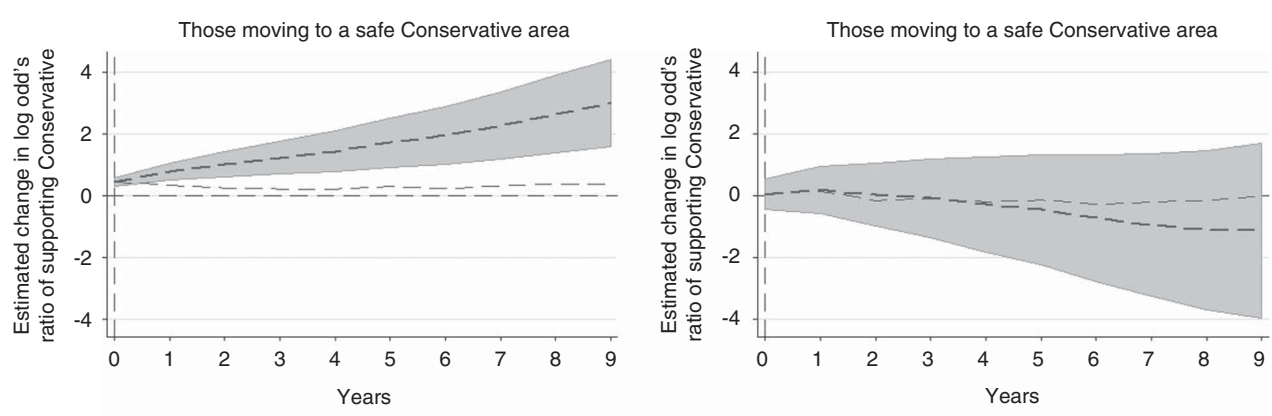

Analysis based on OLS with individual level controls and 9 lags
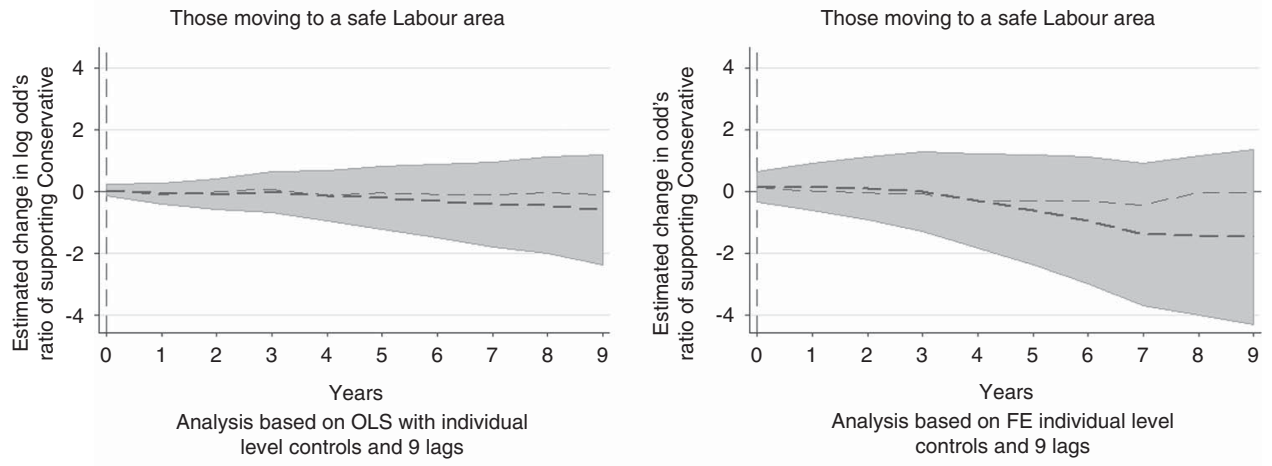

$95 \% \mathrm{Cl} \quad----$ Cumulative Impact

---- - Yearly Impact

Fig. 3. Assimilation to Conservative party support by type of moves over time with extended lags

moving into safe Labour constituencies change only marginally with the introduction of controls in Model 3; these individuals become more left-wing over time, although the effect cannot be distinguished from zero when inference is made to the broader population (five-year cumulative estimate $=-0.865(p<0.772))$.

The introduction of individual fixed effects, to control for time invariant characteristics, in Model 4 reduces the magnitude of the assimilation effects quite substantially, with the contemporaneous coefficient for Conservative constituency moves, in particular, reduced from 0.206 to a statistically non-significant 0.047 . However, while the majority of coefficients are reduced in magnitude, there are exceptions at the three-year and four-year lags for safe Conservative $(0.139 ; p<0.05)$ and safe Labour $(-0.201 ; p<0.01)$ constituency moves, respectively. This suggests that assimilation, rather than occurring immediately after a move, takes place after some years in the new location. For safe Conservative constituency moves, the long-run effect is reduced to 0.428 , but this is still statistically different from zero $(p<0.011)$. For Labour, the long-run multiplier is $-0.200(p<0.310)$ which suggests that the small apparent assimilation effect observed after four years is removed when combined with the effects in the other years.

Finally, Model 5 re-introduces lead dummies in order to control for all forms of self-selecti on in one model. Results suggest that re-introducing the leads has only a small effect on the estimates. The leads are statistically non-significant for those moving to safe Conservative constituencies and have little effect on the coefficient estimates of Model 4. The long-run 
multiplier becomes marginally non-significant in Model 5. However, none of the lead coefficients in Model 5 are themselves significantly different from zero; hence our preferred estimates are those in Model 4. For those moving to safe Labour constituencies, however, there is some limited evidence of political self-selection; two years prior to a move, individuals moving to a safe Labour constituency become somewhat more left-wing, suggesting that move choice is related to prior shifts in political orientation, though the magnitude of the effect is weak. Moreover, political self-selection has no material effect on our conclusions regarding assimilation for those moving to safe Labour constituencies, with the magnitude and significance of the coefficients unaltered by the introduction of the leads.

We now turn to the results for party identification, which are presented in Models 6 to 10 in Table 2. It should be noted that the sample size for some of these models is reduced substantially compared to the linear specifications in Models 1 to 5. This is because relatively few individuals changed their party identification between Labour and the Conservatives during the period of observation and only individuals who change on the outcome contribute to the parameter estimates in a fixed effects model. We must, therefore, be cautious in our interpretation of these models, because our power of inference is weak.

The pattern of coefficients across Models 6 to 10 is quite similar to that found for the left-right scale models. There is evidence in the 'naïve' Models 6, 7 and 8 of political assimilation for individuals moving into safe Conservative constituencies but only weak and inconsistent support for an effect of moves into safe Labour constituencies. Once individual fixed effects are introduced in Models 9 and 10, there is no evidence of assimilation occurring for either type of move. Indeed, these results suggest that individuals moving to safe Conservative constituencies become less likely to support the Conservative party over time, although these estimates are not statistically significant. Long-run multiplier coefficients for those moving into safe Conservative and safe Labour constituencies are also not statistically distinguishable from zero.

Because the BHPS has eighteen waves of data, it is possible to extend the annual lagged and cumulative effects beyond five years after a move. Presentation of these models in tabular form is cumbersome, so we show them in graphical summary form in Figures 2 and 3. We present estimates corresponding to the left-right scale Models 1 and 4 and party support Models 6 and 9 with nine lags instead of five. This provides a contrast between naïve estimation (lags only model) and estimation which is more robust to potential confounders. ${ }^{42}$ Figure 2 shows the effect of moving to safe Conservative and Labour constituencies on left-right attitudes up to nine years after a move.

These longer-run estimates produce similar results to those presented in Table 2; a long-run effect is apparent for left-right attitudes for those moving to a safe Conservative constituency in the model with individual-level controls only. However, once individual fixed effects and time-varying individual level characteristics are controlled for, this long-run effect is approximately halved. There is no commensurate effect on left-right attitudes for individuals moving to safe Labour constituencies, with or without fixed effects. The models for party support in Figure 3 also suggest the presence of an assimilation effect for individuals moving to safe Conservative constituencies, but these are statistically non-significant when individual fixed effects are added to the model. No evidence of assimilation effects is evident for individuals who move to safe Labour constituencies, even before the inclusion of fixed effects.

42 The overall pattern is very similar when using different specifications, e.g. when plotting estimates from Table 2 with five lags or from lag and lead models. The additional plots are available upon request. 


\section{DISCUSSION AND CONCLUSIONS}

In this article we have taken a new approach to addressing an enduring controversy in the study of political behaviour. While theories which posit a causal effect of geographical context on individual political preferences have a long tradition in political science, existing studies have yet to provide convincing evidence that individuals do indeed assimilate, over time, to the majority preferences of the areas in which they live. Our analyses advance the existing stateof-the art in this field by tracking the political preferences of a large sample of individuals over an eighteen-year period. Our analysis used panel data models with fixed effects and controls for time-varying individual characteristics. This longitudinal approach yields a considerably stronger protection against the primary threat to valid causal inference in standard cross-sectional designs, namely that individuals choose which areas they wish to move to (and remain in) and that these choices are themselves correlated with political preferences.

Our results suggest that political assimilation effects were evident in England during the period 1991-2008 but that these were weak and differential across different types of areas. On the one hand, movers to safe Conservative seats became more economically right-wing and more likely to vote Conservative following the move. This suggests that, consistent with the predictions of contextual theories of political behaviour, moving to a more conservative area leads individuals to become more aligned in their political preferences with the local majority. On the other hand, we found no change in left-right attitudes and only very weak evidence of change in party identification amongst movers to safe Labour constituencies.

Several factors may account for the differential assimilation effects across constituency types. First, people who move to a safe Labour area already have a high probability of voting for the Labour party and of having economically left-wing attitudes. Thus, the contingent nature of our findings may be due to a ceiling effect; there is little scope for movers into Labour areas to become more left-wing than they already are immediately prior to moving. An alternative possibility is that the mechanisms through which contextual effects are manifested are less powerful in safe Labour seats. Safe Labour seats are mostly located in urban areas such as London, Birmingham, Manchester, Newcastle upon Tyne and Liverpool. The social pressure to conform to the local majority may be less strong in socially diverse, urban areas than in more homogeneous rural or suburban areas. ${ }^{43}$ Conservatives, who traditionally value conformity to existing social norms, may be more likely than those on the left to pressure newcomers to conform to the local majority position. These possibilities are, however, speculative and it is not possible to establish, with the data available to us, why moving to a Conservative area has an effect on political preferences, while moving to a Labour context does not. Be that as it may, the finding that contexts have heterogeneous effects is important in its own right because it suggests that it is necessary, for a complete account, to clearly specify the conditions under which we should expect areal units to affect political preferences.

With regard to selection into areas, previous studies have demonstrated that American movers, on average, relocate into areas with more congruent political beliefs than the constituencies from which they moved. ${ }^{44}$ Our results show that this kind of geographic sorting generalizes to the British context; an individual's existing political preference is a strong and significant predictor of the political orientation of the area into which he or she moves. However, the finding that citizens relocate to constituencies that are more congruent with their

\footnotetext{
43 Labour constituencies are on average poorer and younger; they have more residents who are tenants, have a low education and are unemployed, but there is more variation in these characteristics across Labour constituencies than across Conservative constituencies.

44 Cho, Gimpel and Hui 2012; Gimpel 1999; McDonald 2011.
} 
existing political beliefs does not imply that the choice of locale is caused by political orientation. In our analysis, when individual level controls are introduced, political preferences prior to the time of moving no longer predict the political orientation of the destination constituency. This suggests that sorting of politically like-minded individuals into areas arises indirectly, because people with different political preferences also have different socioeconomic characteristics which are the actual causal determinants of residential location choices. In short, self-selection into areas appears to be almost entirely non-political in nature.

While our study significantly improves on previous attempts to identify contextual effects, it has limitations of its own which should be acknowledged. In particular our choice of areal unit (Westminster constituencies) can be criticized for inadequately representing the spatial scale at which the mechanisms generally thought to underlie assimilation are likely to operate. Neighbourhood effects theories generally contend that context effects operate primarily through social-psychological processes, such as interpersonal influence and persuasion, which are likely to happen at smaller spatial scales than a parliamentary constituency. Using smaller areal units would almost certainly result in different estimates of assimilation and selection effects than those we have presented here. ${ }^{45}$ While we acknowledge that this problem is pertinent to the interpretation of our findings, we do not believe that it invalidates our findings and conclusions. As we have argued, the constituency is a substantively important context because it is the relevant electoral scale in parliamentary elections and political parties are incentivized to target mobilization efforts strategically across constituencies. In addition, the fact that we find evidence consistent with contextual effects for movers to Conservative constituencies suggests that the null results for some mover types are not due merely to the use of a large areal unit. While we cannot conclude that our results will necessarily generalize across different spatial scales, or to different political contexts, this is not something that we should expect to be the case in any event. The modifiable areal unit problem should not, in short, be taken as a threat to the validity of our conclusions as it is equally pertinent to any spatial scale that an analyst happens, or is able, to select.

A second limitation of our approach is that it overlooks other important ways in which assimilation is likely to take place. In particular, our focus on adult movers means that we cannot draw conclusions about two important groups: young people and those who reside in the same area (or same type of area) for long periods. The places where people live in their childhood, adolescence and early adulthood are likely to shape their political outlook more profoundly than at other times in their lives. ${ }^{46}$ Because we focus only on adults aged 18 and over, we would not detect effects which occur prior to adulthood. And, although it would, in principle, be possible to break our analyses down across age groups, in practice our sample of movers is too small to be able to detect differences between age groups that might exist in the population reliably. Similarly, it is plausible that contextual effects occur for individuals who never move but are nonetheless influenced by the changing political environment within their own locale over time. However, identification of causal assimilation effects for non-movers is a considerably more challenging analytical task than for a sample of movers and consideration of this important group is beyond the scope of this article.

A third limitation of our research is that it only addresses one possible source of heterogeneity in treatment effects (the political hue of the destination constituency). Both individual and contextual characteristics may influence the extent to which individuals adopt the political preferences prevalent in their local environments. For instance, the reasons why individuals

${ }^{45}$ Fotheringham and Wong 1991.

${ }^{46}$ Campbell 2006; Jennings, Stoker and Bowers 2009. 
move - such as getting a new job, moving to a more family-friendly neighbourhood, or attending university - may themselves shape the propensity to assimilate to the new context. Very stable local communities may affect newcomers in different ways than gentrifying communities or places that are growing fast over a specific period of time. Long-distance moves that disrupt social relationships may have different implications for political preferences than short-distance moves where it is easier to maintain pre-existing social networks.

While we acknowledge, then, that our conclusions cannot be generalized without appropriate caution to other spatial levels or to other population sub-groups, we believe that our findings are important nevertheless. The evidence that we have presented suggests that self-selection into areas is considerably more important than assimilation effects in producing the spatial clustering of political preferences long observed by political geographers. This confirms the dominance of selection over assimilation that has been observed in other contexts, including those which have used experimental designs. ${ }^{47}$ We have also shown for the first time that self-selection into areas is almost entirely non-political in nature, in the sense that individuals do not choose where to live on the basis of political preference per se, but as a result of socio-economic characteristics which are jointly correlated with choice of location and political orientation. Location affects individual political preferences, but only weakly, in some areas, and for some outcomes. Thus, while contexts are certainly relevant to our understanding of political preferences, they appear to be considerably less important than proponents of contextual theories have sometimes maintained.

\section{REFERENCES}

Agnew, John A. 1987. Place and Politics: The Geographical Mediation of State and Society. Boston, Mass.: Allen \& Unwin.

Alford, John R., Peter K. Hatemi, John R. Hibbing, Nicholas G. Martin and Lindon J. Eaves. 2011. The Politics of Mate Choice. Journal of Politics 73 (2):362-79.

Allison, Paul D. 1994. Using Panel Data to Estimate the Effects of Events. Sociological Methods \& Research 23:174-99.

Andersen, Robert, and Anthony Heath. 2002. Class Matters: The Persisting Effects of Contextual Social Class on Individual Voting in Britain, 1964-97. European Sociological Review 18 (2):125-38.

Baybeck, Brady, and Scott D. McClurg. 2005. What Do They Know and How Do They Know It? American Politics Research 33 (4):492-520.

Blanden, Jo, Franz Buscha, Patrick J. Sturgis and Peter Urwin. 2012. Measuring the Earnings Returns to Accredited Adult Learning in the UK. Economics of Education Review 31 (4):501-14.

Books, John, and Charles Prysby. 1988. Studying Contextual Effects on Political Behavior. American Politics Research 16 (2):211-38.

Burbank, Matthew J. 1997. Explaining Contextual Effects on Vote Choice. Political Behavior 19 (2):113-32.

Butler, David, and Donald E. Stokes. 1974. Political Change in Britain: The Evolution of Electoral Choice. London: Macmillan.

Campbell, David E. 2006. Why We Vote: How Schools and Communities Shape Our Civic Life. Princeton, N.J.: Princeton University Press.

Champion, Tony. 2005. Population Movement within the UK. Pp. 91-113 in Focus on People and Migration, edited by Edward R. Chappell. Basingstoke, Hants.: Palgrave.

Chen, Jowei, and Jonathan Rodden. 2009. Tobler's Law, Urbanization, and Electoral Bias: Why Compact, Contiguous Districts are Bad for the Democrats. Working paper, Department of Political Science, Stanford University, Palo Alto, Calif.

Cho, Wendy Tam, James G. Gimpel and Iris S. Hui. 2012. Voter Migration and the Geographic Sorting of the American Electorate. Annals of the Association of American Geographers 103 (4):856-70.

${ }^{47}$ Katz, Kling and Liebman 2001; Ludwig, Duncan and Hirschfield 2001; Ludwig et al. 2008. 
Cho, Wendy Tam, and Thomas J. Rudolph. 2008. Emanating Political Participation: Untangling the Spatial Structure behind Participation. British Journal of Political Science 38 (2):273-89.

Cox, Kevin R. 1969. The Voting Decision in a Spatial Context. Progress in Geography 1:81-117.

Crewe, Ivor, and Clive Payne. 1976. Another Game with Nature: An Ecological Regression Model of the British Two-Party Vote Ratio in 1970. British Journal of Political Science 6 (1):43-81.

Cutler, Fred. 2007. Context and Attitude Formation: Social Interaction, Default Information, or Local Interests? Political Geography 26 (5):575-600.

Cutts, David, and Edward Fieldhouse. 2009. What Small Spatial Scales are Relevant as Electoral Contexts for Individual Voters? The Importance of the Household on Turnout at the 2001 General Election. American Journal of Political Science 53 (3):726-39.

Denver, David T., and Gordon Hands. 1997. Modern Constituency Electioneering: Local Campaigning in the 1992 General Election. Abingdon, Oxon.: Routledge.

Dunleavy, Patrick. 1979. The Urban Basis of Political Alignment: Social Class, Domestic Property Ownership and State Intervention in Consumption Processes. British Journal of Political Science 9 (4):409-43.

Ethington, Philip J., and Jason A. McDaniel. 2007. Political Places and Institutional Spaces: The Intersection of Political Science and Political Geography. Annual Review of Political Science 10:127-42.

Evans, Geoffrey, Anthony Heath and Mansur Lalljee. 1996. Measuring Left-Right and LibertarianAuthoritarian Values in the British Electorate. British Journal of Sociology 47 (1):93-112.

Florida, Richard. 2003. Cities and the Creative Class. City \& Community 2:3-19.

Fotheringham, Alexander S., and David W. S. Wong. 1991. The Modifiable Areal Unit Problem in Multivariate Statistical Analysis. Environment and Planning A 23 (7):1025-44.

Gimpel, James G. 1999. Separate Destinations: Migration, Immigration, and the Politics of Places. Ann Arbor: University of Michigan Press.

Halaby, Charles N. 2003. Panel Models for the Analysis of Change and Growth in Life Course Studies. Pp. 503-27 in Handbook of the Life Course, edited by J. Mortimer and M. Shanahan. New York: Kluwer Academic/Plenum Publishers.

2004. Panel Models in Sociological Research: Theory into Practice. Annual Review of Sociology 30:507-44.

Heath, Anthony, Geoffrey Evans and Jean Martin. 1994. The Measurement of Core Beliefs and Values: The Development of Balanced Socialist/Laissez Faire and Libertarian/Authoritarian Scales. British Journal of Political Science 24 (1):115-32.

Huckfeldt, Robert, Ikeda Ken'ichi and Franz. U. Pappi. 2005. Patterns of Disagreement in Democratic Politics: Comparing Germany, Japan, and the United States. American Journal of Political Science 49 (3):497-514.

Huckfeldt, Robert, and John D. Sprague. 1992. Political Parties and Electoral Mobilization: Political Structure, Social Structure, and the Party Canvass. American Political Science Review 86 (1): 70-86.

1995. Citizens, Politics, and Social Communication. New York: Cambridge University Press.

Jennings, M. Kent, Laura Stoker and Jake Bowers. 2009. Politics across Generations: Family Transmission Reexamined. Journal of Politics 71 (3):782-99.

Johnston, Ron J., Kelvyn Jones, Rebecca Sarker, Carol Propper, Simon Burgess and Anne Bolster. 2004. Party Support and the Neighbourhood Effect: Spatial Polarisation of the British Electorate, 1991-2001. Political Geography 23 (4):367-402.

Johnston, Ron J., Kelvyn Jones, Carol Propper and Simon Burgess. 2007. Region, Local Context, and Voting at the 1997 General Election in England. American Journal of Political Science 51 (3): 640-54.

Johnston, Ron J., and Charles J. Pattie. 2006. Putting Voters in Their Place: Geography and Elections in Great Britain. Oxford: Oxford University Press.

Johnston, Ron J., Charles J. Pattie and Graham Allsopp. 1988. A Nation Dividing? The Electoral Map of Great Britain, 1979-1987. London: Longman. 
Johnston, Ron J., Charles J. Pattie, Danny F. L. Dorling, Ian MacAllister, Helena Tunstall and David J. Rossiter. 2001. Social Locations, Spatial Locations and Voting at the 1997 British General Election: Evaluating the Sources of Conservative Support. Political Geography 20 (1):85-111.

Johnston, Ron, Carol Propper, Simon Burgess, Rebecca Sarker, Anne Bolster and Kelvyn Jones. 2005. Spatial Scale and the Neighbourhood Effect: Multinomial Models of Voting at Two Recent British General Elections. British Journal of Political Science 35 (3):487-514.

Katz, Lawrence F., Jeffrey R. Kling and Jeffrey B. Liebman. 2001. Moving to Opportunity in Boston: Early Results of a Randomized Mobility Experiment. Quarterly Journal of Economics 116 (2): 607-54.

Kelley, Jonathan, and Ian McAllister. 1985. Social Context and Electoral Behavior in Britain. American Journal of Political Science 29 (3):564-86.

King, Gary. 1996. Why Context Should Not Count. Political Geography 15:159-64.

Laporte, Audrey, and Frank Windmeijer. 2005. Estimation of Panel Data Models with Binary Indicators when Treatment Effects Are Not Constant over Time. Economics Letters 88 (3):389-96.

Ludwig, Jens, Greg J. Duncan and Paul Hirschfield. 2001. Urban Poverty and Juvenile Crime: Evidence from a Randomized Housing-Mobility Experiment. Quarterly Journal of Economics 116 (2): 655-79.

Ludwig, Jens, Jeffrey B. Liebman, Jeffrey R. Kling, Greg J. Duncan, Lawrence F. Katz, Ronald C. Kessler, and Lisa Sanbonmatsu. 2008. What Can We Learn about Neighborhood Effects from the Moving to Opportunity Experiment? American Journal of Sociology 114 (1):144-88.

McAllister, Ian, Ron J. Johnston, Charles J. Pattie, Helena Tunstall, Danny F. L. Dorling and David J. Rossiter. 2001. Class Dealignment and the Neighbourhood Effect: Miller Revisited. British Journal of Political Science 31 (1):41-59.

McAllister, Ian, and Donley T. Studlar. 1992. Region and Voting in Britain, 1979-87: Territorial Polarization or Artifact? American Journal of Political Science 36 (1):168-99.

McDonald, Ian. 2011. Migration and Sorting in the American Electorate: Evidence from the 2006 Cooperative Congressional Election Study. American Politics Research 39 (3):512-33.

Miller, William L. 1978. Electoral Dynamics in Britain since 1918. New York: St Martin's Press.

Molloy, Raven, Christopher L. Smith and Abigail K. Wozniak. 2011. Internal Migration in the United States. Washington, D.C.: National Bureau of Economic Research.

Norris, Pippa. 2005. The British Parliamentary Constituency Database. 1992-2005. Release 1.3.

Pattie, C., and R. Johnston. 2000. 'People Who Talk Together Vote Together': An Exploration of Contextual Effects in Great Britain. Annals of the Association of American Geographers 90:41-66.

Pattie, Charles J., Ron J. Johnston, and Edward A. Fieldhouse. 1995. Winning the Local Vote: The Effectiveness of Constituency Campaign Spending in Great Britain, 1983-1992. American Political Science Review 89 (4):969-83.

Rabe, Birgitta, and Mark Taylor. 2010. Residential Mobility, Quality of Neighbourhood and Life Course Events. Journal of the Royal Statistical Society: Series A (Statistics in Society) 173:531-55.

Rodden, Jonathan. 2010. The Geographic Distribution of Political Preferences. Annual Review of Political Science 13:321-40.

- 2012. The Long Shadow of the Industrial Revolution. Unpublished manuscript. Stanford University Calif.

Sturgis, Patrick. 2002. Attitudes and Measurement Error Revisited: A Reply to Johnson and Pattie. British Journal of Political Science 32 (4):691-98.

Taylor, Peter J., and Ron J. Johnston. 1979. Geography of Elections. London: Croom Helm.

Tiebout, Charles M. 1956. A Pure Theory of Local Expenditures. Journal of Political Economy 64:416-24.

Wooldridge, Jeffrey M. 2002. Econometric Analysis of Cross Section and Panel Data. Cambridge, Mass.: MIT Press. 